\title{
LEITURA E PRODUÇÃO TEXTUAL NA EJAI: um caminho necessário
}

\author{
Reading and textual production in EJAI: a necessary path
}

PABLO RODRIGO DA SILVA MARTINS ${ }^{1}$

\begin{abstract}
RESUMO: O presente estudo tem por objetivo refletir sobre a relevância da prática de Leitura e Produção de textos na Educação de Jovens, Adultos e Idosos (EJAI) como caminho necessário, visto que, através dessas práticas, há a possibilidade da aproximação entre texto trabalhado e o contexto do educando, para que este possa agir de forma consciente no meio social, bem como há a possibilidade de que o aluno se torne usuário proficiente da língua.
\end{abstract}

Palavras-chave: EJAI. Leitura. Produção textual.

ABSTRACT: This study aims to reflect on the relevance of the practice of reading and production of texts in the Education of Youth, Adults and Seniors (EJAI) as a necessary way because, through these practices, there is the possibility of rapprochement between working text and educating the context, so that it can act consciously in the social environment, and there is the possibility that the student becomes proficient user of the language.

Key words: EJAI. READING. TEXT PRODUCTION

\section{INTRODUÇÃO}

O trabalho docente na Educação de Jovens, Adultos e Idosos $\left(\mathrm{EJAI}^{2}\right)$ perpassa pela adoção de estratégias que respeitem o universo plural dos alunos e atenda a seus anseios. Em relação ao ensino-aprendizagem de Língua Portuguesa, esse processo requer atenção ainda maior, pois através dos mecanismos da Língua, o discente pode desenvolver habilidades necessárias à vida em sociedade. Pressupõe-se que a escola propicie um ambiente favorável à formação de leitores e produtores de textos proficientes, ou seja, aqueles capazes de estabelecer seus próprios objetivos de leitura, relacionando o texto ao contexto.

Desse modo, o professor deve trabalhar o texto de forma completa e não fragmentando o todo, visto que os processos que envolvem a prática de leitura e produção textual devem voltar-se

\footnotetext{
${ }^{1}$ Professor do IFPI. Mestre em Letras pela UESPI. Email: pablo.martins@ififi.edu.br

${ }^{2}$ Apesar de os documentos oficiais considerarem apenas a Educação de jovens e adultos, aqui, neste texto, utilizar-seá Educação de Jovens, Adultos e Idosos numa perspectiva inclusiva e que respeita as diversidades do corpo discente dessa modalidade.
} 
a uma ordem político-social, a partir do momento em que tais práticas corroboram com a formação de sujeitos agentes e críticos. E assim, há a conciliação entre os objetivos da prática textual e as concepções da Educação de Jovens, Adultos e Idosos.

Nesse sentido, as conjecturas que alimentaram essa pesquisa foram o fato de que as Práticas de Leitura e Produção de textos na EJAI devem ser pautadas em práticas significativas, e também na relevância de tais práticas na formação de cidadãos conscientes em relação ao meio em que estão inseridos.

Assim, o presente estudo objetiva refletir acerca da relevância da leitura e da produção textual para a aprendizagem significativa de alunos da EJAI. Para a concretização desse intento, utilizou-se a pesquisa bibliográfica de cunho qualitativo; alicerçando-nos, principalmente, nos estudos dos seguintes teóricos: Carvalho (2010), Freire (1996), Dionísio (2005), dentre outros não menos importantes.

O texto está dividido em cinco partes. Inicialmente, é feita uma introdução global sobre a pesquisa; em seguida localiza-se a EJAI na história; depois centra-se o texto nos sujeitos da EJAI; após, há uma explanação sobre a Leitura e Produção de textos como ferramentas necessárias à EJAI. Por fim conclui-se o texto apresentando as considerações finais sobre a temática.

\section{O CONTEXTO HISTÓRICO DA EJAI}

As pesquisas que têm por alvo a Educação de Jovens, Adultos e Idosos (EJAI) afirmam que, por longos anos, essa modalidade foi marcada por campanhas educacionais estritamente emergenciais, visto que visavam apenas levar o aluno a ler e escrever, divergindo do fato de que as práticas na EJAI devem contemplar competências e habilidades que vão além, possibilitando o desenvolvimento do indivíduo em seu aspecto global e não apenas voltado para o conteúdo. Como as primeiras concepções da EJAI contrariaram esse universo tão plural que envolve as práticas pedagógicas, elas foram marcadas muitas vezes pelo fracasso.

As concepções de EJAI, no Brasil, estiveram atreladas aos modelos econômicos, políticos e sociais em voga. As primeiras concepções estão ligadas ao modelo fundado pelos jesuítas, à época da colonização. Esse processo estava ligado à tentativa de aculturação dos indígenas, a fim de que a Igreja Católica e a realeza concretizassem seus objetivos. Aquela procurava converter os nativos à fé cristã, assim, os jesuítas dedicaram-se à pregação do cristianismo e ao trabalho educativo; esta buscava a expansão de seus territórios e o acúmulo de riquezas. Dessa forma, os jesuítas eram os promotores e organizadores dos processos educacionais. Entretanto, esse cenário passou por transformações por alguns motivos, dentre os quais se destaca a vinda da família real ao Brasil. Nesse momento, houve a necessidade de se 
atender a demanda criada pela aristocracia, bem como preparar as pessoas para ocuparem os cargos técnicos recém-criados.

Com o crescente processo de urbanização, surge a necessidade do domínio do conhecimento e de habilidades de trabalho. Assim, surgem as primeiras escolas noturnas incentivadas pela crise do sistema escravocrata, porém o índice de evasão foi muito grande, contribuindo com o fracasso escolar.

Após a Primeira Guerra Mundial e a crescente industrialização, consolida-se uma nova classe social: a burguesia. Essa emergente parcela da sociedade exige o acesso à educação voltado à academia, restrita à elite, ao mesmo tempo em que às camadas populares era relegado o analfabetismo. O período pós-Revolução de 30 permite a concretização de um sistema educacional significativo à EJAI, passando a ser exigida a ampliação da escolaridade de jovens, adultos e idosos. Paiva citada por Carvalho (2010, p.17) afirma que "a partir da Revolução de 30 encontramos no país movimentos de educação de adultos de alguma significação". Já o período compreendido entre as décadas de 40 e 50 é marcado pela relevância dispensada à EJAI. A política educacional floresce, fazendo surgir a Campanha de Educação de Adolescentes e Adultos - CEAA, a regulamentação do Fundo Nacional de Ensino Primário - FNPE, a criação do INEP, o I Congresso Nacional de Educação de Adultos e o Seminário Internacional de Educação de Adultos. Nesse ínterim, ganha notoriedade o professo Paulo Freire, que segundo Carvalho (2010)

Pretendia que a educação libertasse os oprimidos da condição de pobreza e inferioridade em que viviam. A educação libertadora de Freire se opunha ao conceito, também proposto por ele, de educação bancária, aquela que julga possível e suficiente depositar conhecimentos na cabeça do educando, como quem põe dinheiro. (CARVALHO, 2010, p. 39)

Como os jovens, adultos e idosos não se alfabetizavam no período adequado, restava a EJAI uma forma de recuperar o tempo perdido. Assim, a alfabetização desse público representava a possibilidade de transformação na vida dessas pessoas que ultrapassavam as barreiras dos conteúdos formais. O professor Paulo Freire defendia a educação como ferramenta de libertação dos sujeitos e transformação das realidades. $O$ momento de luzes verificado nesse período é cessado por conta da Ditadura Militar. Houve uma estagnação no processo de evolução das ações educacionais voltadas aos jovens, adultos e idosos. É criado, em 1967, o MOBRAL - Movimento Brasileiro de Alfabetização. Nos dizeres de Carvalho (2010),

Propunha-se a "conduzir a pessoa humana a adquirir técnicas de leitura, escrita e cálculo como meio de integrá-la a sua comunidade, permitindo melhores condiçôes de vida". O objetivo era que o indivíduo adquirisse técnicas (ler, escrever, contar) para se integrar na comunidade e alcançar melhores condições de vida. (CARVALHO, 2010, p 43. Grifos do autor) 
Esse movimento alinhava o processo de alfabetização aos interesses políticos do Regime, fazendo surgir os analfabetos funcionais, ou seja, alunos que foram ensinados a ler e a escrever, porém não conseguiam interpretar além das linhas do texto. Tal concepção de EJAI divergia dos princípios defendidos por Freire, visto que o Estado objetivava formar cidadãos integrados ao modelo governista. No final desse período, ampliou-se a EJAI muito por conta da inserção cada vez mais cedo dos jovens no mercado de trabalho, restando a eles a educação no turno noturno, pois o Governo incentivava que os trabalhadores fossem produtivos e aptos a obter melhores salários.

Com a redemocratização do país, o foco da EJAI volta-se basicamente para a extinção do analfabetismo e a capacitação dessa clientela ao mercado de trabalho, dando à educação um caráter permanente e significativo, concretizando o que a Constituição promulgada em 1988, em seu Art. 208, reza: “O dever do Estado com a educação será efetivado mediante a garantia de: I ensino fundamental obrigatório e gratuito, assegurada, inclusive sua oferta gratuita para todos os que a ele não tiveram acesso na idade própria”.

No governo Sarney, criou-se a Fundação Educar com o intuito de supervisionar e acompanhar o trabalho desenvolvido pelos sistemas de ensino pelo país, repassando a eles recursos financeiros para a manutenção do programa. Ao assumir o poder, Fernando Collor de Melo extinguiu a Fundação Educar e anunciou o Plano Nacional de Alfabetização e Cidadania, que de modo geral, consistia em distribuir recursos para a alfabetização de crianças, jovens e adultos. Fernando Henrique Cardoso, ao se tornar presidente da República institui o PAS Programa Alfabetização Solidária, que, de acordo com Carvalho (2010, p. 46) “destinava-se a alfabetizar jovens e adultos moradores dos municípios mais pobres, de baixo índice de desenvolvimento humano (IDH), com elevados percentuais de analfabetismo".

O Programa Brasil Alfabetizado foi a iniciativa relacionada à EJAI no governo Lula, e foi criado para promover o acesso à educação como um direito de todos, e também preparar alfabetizadores para alfabetizar cidadãos com 15 anos ou mais. Esta última iniciativa permanece até os dias atuais concomitante à instituição da EJAI como modalidade de ensino, que tem suas Diretrizes Curriculares Nacionais estabelecida pela Resolução no 1 CNE/CEB de 5 de julho de 2000 que em seu Art. 5, Parágrafo Único, afirma que:

Como modalidade destas etapas da Educação Básica, a identidade própria da Educação de Jovens e Adultos considerará as situações, os perfis dos estudantes, as faixas etárias e se pautará pelos princípios de equidade, diferença e proporcionalidade na apropriação e contextualização das diretrizes curriculares nacionais e na proposição de um modelo pedagógico próprio. 
Assim, a EJAI atravessou um longo percurso desde os primórdios da Colonização até os dias atuais. Acompanhando as estruturas políticas, econômicas e sociais vigentes, voltou-se ora à manutenção da ordem vigente, ora a uma tentativa de transformação social, até ser transformado em modalidade de ensino, sendo prevista na Constituição Federal e também na Lei de Diretrizes Curriculares da Educação Nacional (LDB - 9394/96), dessa forma, entre avanços e retrocessos tornou-se permanente e obrigatória, cristalizando-se como uma conquista como política de acesso à educação de qualidade e de equidade de oportunidades com o ingresso ou reingresso educacional.

\section{OS SUJEITOS DA EJAI}

Um fato passível de ser constatado na grande maioria das turmas da EJAI é a elevada taxa de evasão nas turmas, gerando o fracasso escolar, resultado de inúmeros fatores, tais como: a baixa autoestima dos alunos, preconceito da sociedade, metodologias de ensino inadequadas etc. Nesse sentido, quem são os alunos-sujeito da EJAI? Por que buscam a escola? Como são vistos pelos professores e como os veem? Quais os saberes que carregam consigo? Esses e outros questionamentos nortearão esse tópico do texto.

Ao se pensar a EJAI do ponto de vista de seus alunos-sujeito, evidenciam-se marcas que os caracterizam. É notória a diversidade etária, cultural, racial, de credo; contudo, essa diversidade é substituída pela uniformidade quando o assunto é a origem social. Jovens, adultos e idosos se misturam em um ambiente único e ali convivem por um determinado período. São sujeitos oriundos de classes sociais marginalizadas, que não tiveram oportunidade de ensino, ou, quando tiveram, não permaneceram. Entanto, buscam na EJAI uma correção em relação a suas vidas escolares. Nesse sentido, Freire (1996) assevera que

(...) Pensar certo coloca ao professor ou, mais amplamente, à escola, o dever de não só respeitar os saberes com que os educandos, sobretudo os das classes populares, chegam a ela saberes socialmente construídos na prática comunitária - mas também (...) discutir com os alunos a razão de ser de alguns desses saberes em relação com o ensino dos conteúdos. (FREIRE, 1996, p. 30)

Afirmando o acima exposto, o teórico corrobora com o fato de que os saberes múltiplos dos alunos da EJAI são fundamentais no processo de ensino-aprendizagem de quaisquer disciplinas ministradas seja no Ensino Fundamental, seja no Ensino Médio. Portanto, o ensinar, na EJAI, exige respeito aos conhecimentos prévios do corpo discente da escola. Em regra, o aluno da EJAI carrega em si uma gama de conhecimentos adquiridos cotidianamente em suas relações com o outro, e são esses conhecimentos em suma informais que devem ser o ponto de 
partida para a prática docente. O Caderno Trabalhando com a Educação de Jovens e Adultos, produzido pelo MEC, em seu fascículo relativo aos Alunos e Alunas da Educaşão de Jovens e Adultos afirma que

Esse saber, fundado no cotidiano, é uma espécie de saber das ruas, frequentemente assentado no "senso comum" e diferente do elaborado conhecimento formal com que a escola lida. É também um conhecimento elaborado, mas não sistematizado. É um saber pouco valorizado no mundo letrado, escolar e, frequentemente, pelo próprio aluno. Nesse sentido, qualquer forma de discriminação no exercício do professor pode ocasionar resultados incorrigíveis, como a evasão. (BRASIL, 2006, p. 7)

Os múltiplos saberes carregados pelo discente da EJAI são originados por suas relações sociais, por suas experiências diárias; e por ser gerado a partir desses movimentos, erroneamente são desconsiderados no processo de ensino-aprendizagem, por divergirem do caráter técnico que está envolto no ambiente escolar, e essa situação recorrentemente resulta na desqualificação dos saberes extraescolares responsáveis pela constituição do sujeito.

A relação do aluno da EJAI com a escola está marcado por um movimento de atração e repulsa e está relacionado a diversos aspectos. Eles buscam satisfação pessoal, há exigências no emprego, há a necessidade de interação e integração com a sociedade, de se sentirem mais ativos no meio em que vivem. Ao adentrar no ambiente escolar, esses alunos esperam que as estratégias de ensino sejam pautadas no tradicionalismo, ou seja, que o professor seja aquele transmissor de conteúdos e que mantenha a postura do único detentor do saber, enquanto que o aluno deva se comportar como um depósito de conhecimento. Porém, ao se deparar com uma situação diferente, ele se sente inquieto e às vezes incomodado com um ambiente escolar mais sociável e propício à construção de saberes e à troca de experiências. O Caderno já citado acima assevera que:

Muitos, ao se depararem com uma aula na qual são convidados a pensar juntos, em grupo; a resolver desafios diferentes dos exercícios mais convencionais; a ler textos literários; a aprender com a música, a poesia, o jornal; a fazer matemática com jogos e cálculos diversos, construir projetos; estranham, resistem e acreditam não ser esse o caminho para aprender o que a escola ensina. (BRASIL, 2006, p. 8-9).

Essa resistência, por muitas vezes, funciona como termômetro entre o professor e o aluno, visto que essa relação, nos primeiros dias, é marcada pela postura adotada pelo docente. E nesse sentido, este tem de atentar-se ao fato de que o público da EJAI ainda traz em si uma postura arraigada a um contexto educacional inadequado às aspirações sociais atuais. Ao adotar metodologias nas quais o aluno é levado a interagir com os outros e com o conteúdo, o professor rompe com um estigma construído pelo aluno à época em que esteve na escola, ou se lá nunca esteve, ele o construiu baseado em vivências de terceiros. 
Dessa forma, percebe-se que o aluno da EJAI se apresenta ao contexto escolar como um ser único, detentor de saberes práticos, e que, ao buscar a escola, busca também o tempo perdido, a possibilidade de ser reconhecido pelos outros, dentre outros aspectos.

\section{UM CAMINHO NECESSÁRIO À EJAI}

A busca de uma EJAI adequada ao atual contexto social perpassa por uma prática pedagógica atenta aos anseios de sua exigente clientela. E esta adequação está intimamente relacionada à prática de Leitura e Produção textual, visto que, através dessa prática, o aluno da EJAI pode interpretar o mundo coerentemente e se tornar um ser crítico e atuante.

As recentes medidas governamentais relacionadas ao novo contexto da EJAI redefiniram as práticas educacionais relacionadas a esse segmento da educação básica. O princípio da equiparação e da diferença deve prevalecer em detrimento de antigas práticas arraigadas num contexto que prevalecera antigamente.

Ao se atribuir importância à EJAI, a sociedade atual reconhece-a como meio que busca diminuir a distância de muitas pessoas em relação à aprendizagem, e essa modalidade de ensino tende a se tornar mais atrativa e significativa se adotar, em suas práticas pedagógicas, a leitura e produção de texto, visto que tais práticas aproximam a teoria e a prática, tornando o processo de ensino-aprendizagem mais acessível e adequado. Nesse sentido, Bajard (2007, p. 10) afirma que "Os métodos ativos preconizam que as aprendizagens fundamentais sejam construídas dentro de uma prática de linguagem".

É notório que a aprendizagem de um indivíduo está intimamente ligada a suas estruturas do pensamento e o contexto em que ele está inserido. E esse processo se dá de forma significativa se forem confrontados os conteúdos vistos em sala de aula com suas práticas sociais, possibilitando ao ser uma interação com os fatos sociais. Segundo Matta,

Podemos trabalhar, como exercício de leitura, primeiramente com aqueles textos que circulam naturalmente no nosso cotidiano. Ao fazer isso devemos observar um ponto inicial: a forma de composição - o formato com que cada texto se apresenta (MATTA, 2009, p. 80).

A teórica, ao destacar a importância da adequação dos textos com o contexto em que o aluno está inserido, fundamenta e valida a relação intima entre as práticas educacionais e o ambiente sociocultural do educando. Corroborando ao que a autora acima mencionada, Moreira citado por Naspolini (2009, p. 14) assevera que "o conhecimento prévio é isoladamente, a variável que mais influencia a aprendizagem. Em última análise, só podemos aprender a partir daquilo que já conhecemos". E a possível relação teoria e prática mencionada se apresenta 
adequadamente ao contexto da Educação de Jovens, Adultos e Idosos; visto que a clientela desse segmento exige tratamento diferenciado e adequado. Os discentes precisam se perceber, serem reflexos daquilo que veem em sala.

Essa concepção de prática e produção de texto está voltada para todos os níveis da educação básica. Incluindo-se nesse contexto, a EJAI encontra na leitura e na produção de textos ferramentas relevantes para a concretização do processo de ensino e aprendizagem; pois que através da leitura, o aluno da EJAI entra em contato com vários textos, nos quais é refletido o ambiente em que ele vive.

A proposta da EJAI, na sociedade brasileira atual, está voltada para a qualidade e respeito às pessoas que buscam concluir a trajetória escolar, possibilitando-as uma inserção e adequação à modernidade pela qual o mundo vive. Para isso, as Diretrizes Curriculares Nacionais para a EJAI redefiniu esta como integrante da Educação Básica, sendo assim, direito do cidadão. A Proposta Curricular para a Educação de Jovens, Adultos e Idosos afirma que

Os cursos destinados à Educação de Jovens e Adultos devem oferecer a quem os procura tanto a possibilidade de desenvolver as competências necessárias para a aprendizagem dos conteúdos escolares, quanto a de aumentar sua consciência em relação ao estar no mundo (BRASIL, 2002 p. 11).

Com isso, foram deixadas no passado ideias retrógradas como compensação do que se perdeu ou a busca do tempo perdido; para vigorar as relações de equidade e qualidade: aquela está relacionada ao caráter igualitário de direitos e oportunidades à educação; esta se volta para a identificação, reconhecimento e respeito às diferenças de jovens, adultos e idosos.

Através da leitura e da produção de texto, o aluno, principalmente o da EJAI é capaz de se tornar um cidadão apto a conviver em sociedade, ser livre, crítico e pensante; pois com o exercício de tais métodos ele consegue enxergar o mundo que o rodeia com outros olhos, pois a leitura e a produção de texto ampliam os horizontes interpretativos do aluno. Importante frisar que essas leituras, como também as práticas textuais devem estar voltadas para o mundo onde está inserido o indivíduo, pois segundo Street citado por Vóivio (2007), “A construção do letramento está imbricada nas práticas discursivas e nas relações de poder na vida cotidiana: está socialmente construída, materialmente produzida, moralmente regulada e tem significado simbólico que não pode reduzir-se a nenhum destes”. (Street apud Vóivio, 2007. p.88).

Assim, as práticas pedagógicas, e aqui se incluem a seleção dos textos, devem obedecer ao caráter da diferença no processo de letramento, ou seja, processo em que o aluno consegue lê e compreender de forma coerente o mundo que o circunda como também escrever sobre ele.

Dessa forma a prática da leitura e da produção de texto na EJAI deve buscar preencher lacunas da aprendizagem abertas pela inserção tardia no ensino. Também, os textos a serem 
trabalhados devem adequar-se às complexidades culturais de hoje. De acordo com Dionísio (2005),

(...) manter um repertório vasto e flexível de práticas, desempenhar papéis e ativar recursos que deem expressão às dimensões operativas, culturais e críticas, atuando, tanto: como decodificador, pela mobilização de recursos necessários para abrir o código dos textos escritos, reconhecendo e usando traços e estruturas convencionais da organização do texto; como participante textual, participando na construção de sentidos, tendo consideração, por relação com suas experiências e conhecimentos sobre outros discursos, textos e sistemas de significação, os sistemas de sentido específicos de cada texto; como utente [usuário] de textos, usando-os pragmaticamente, negociando as relações sociais à volta dos textos, sabendo sobre eles e agindo nas diferentes funções sociais e culturais que eles desempenham na sociedade (por exemplo, na escola) e compreendendo que estas funções afetam o modo como os textos são estruturados, o seu tom, o seu grau de formalidade e a organização dos seus elementos constitutivos (DIONÍSIO, 2005, p.76)

Então, segundo a autora acima citada, no processo de letramento, a seleção dos textos explorados no processo de aprendizagem deve obedecer a critérios que estejam ligados às diversas relações sociais que o aluno constrói diariamente dentro e fora da escola. E essa seleção se mostra ainda mais importante na EJAI, visto que a clientela, em muitos casos, necessita de algo a mais que o fixe em sala de aula. Assim, se ele trabalhar com textos onde se reconheçam a dedicação aos estudos tende a ser mais significativa. A escola deve-se apresentar como espaço para a ampliação da sociabilidade, bem como do horizonte crítico do aluno, transformando-o em um ser ativo e crítico sobre aquilo que o circunda.

Assim, percebe-se que a prática em Língua Portuguesa, através da leitura e produção de textos, configura-se como meio imprescindível e um caminho necessário à EJAI, a partir do momento em que possibilita ao discente dessa modalidade a apreensão significativa dos mecanismos da Língua ao confrontar teoria e prática; bem como possibilita sua participação na sociedade de forma efetiva ao desenvolver e exercitar o criticismo em seu cotidiano, tornando-o sujeito de seu tempo e de suas relações sociais.

\section{CONSIDERAÇÕES FINAIS}

Num processo de atração e repulsão, a EJAI esteve presente durante boa parte da história brasileira. Alvo de pesquisas em torno de suas concepções e suas práticas, adaptou-se ao contexto social vigente e assim. Ao atender uma clientela que ao mesmo tempo é uma, pois os que a buscam são aqueles que não conseguiram prosseguir com os estudos; ela se torna plural, pois lida com as diversas subjetividades inerentes ao sujeito. Sujeito este, que necessita, em muitos casos, alargar seus horizontes. 
É parte integrante desse contexto a Língua Portuguesa, no momento em que possibilita a concretização dos objetivos básicos da EJAI. Possibilitando o contato dos alunos com diversos textos, incentivando a interação entre o leitor/produtor com o texto, o professor pode transportar o educando ao contexto em que vive e a partir disso, fazer com que ele, sujeito passivo socialmente transforme-se, transformando também suas práticas.

Dessa forma, pode-se concluir que a prática de leitura e produção textual é um caminho necessário à EJAI, pois através disso, o aluno aproxima suas realidades vivenciadas diariamente ao contexto educacional, diminuindo o abismo existente entre a sala de aula e o mundo real; bem como pode transformar-se em usuário proficiente da Língua Materna, utilizando-a adequadamente aos diversos contextos possíveis.

\section{REFERÊNCIAS}

BAJARD, E. Da escuta de textos à leitura. São Paulo: Cortez, 2007.

BRASIL. Ministério da Educação. Secretaria de Educação Fundamental. Proposta curricular para a educação de jovens e adultos: segundo segmento do Ensino Fundamental. $5^{a}$ a $8^{a}$ séries. Brasília: MEC/SEF, 2002. BRASIL. Lei de Diretrizes e Bases da Educação Nacional (LDB) - Lei no $9394-96$

. Coleção Cadernos da EJA. Ministério da Educação - MEC, Secretaria de Educação Continuada, Alfabetização e Diversidade - SECAD, 2006.

CARVALHO, Marlene. Primeiras letras: alfabetização de jovens e adultos em espaços populares. São Paulo: Ática, 2010.

DIONÍSIO, M. de L. (2005) Literatura, leitura e escola: uma hipótese de trabalho para a construção do leitor cosmopolita. In: PAIVA, A.; MARTINS, A.; PAULINO, G.;

FREIRE, Paulo. Pedagogia da autonomia: saberes necessários à prática educativa. São Paulo: Paz e Terra, 1996.

MATTA, Sozângela Schemim da. Português - Linguagem e Interação. Curitiba: Bolsa Nacional do Livro Ltda. 2009.

NASPOLINI, Ana Tereza. Tijolo por tijolo: prática de ensino de língua portuguesa. São Paulo: FTD, 2009.

VÓIVIO, Cláudia Lemos. Prática de leitura na EJA: do que estamos falando e o que estamos aprendendo. In REVEJ@ - Revista de Educação de Jovens e Adultos, v. 1, n. 0, p. 1-108, ago. 2007. 